\title{
CLINICAL RESULTS AND REOPERATION RATES AFTER LONG ADULT DEFORMITY FUSIONS FROM THE SACRUM TO THE THORACOLUMBAR SPINE
}

\author{
๑ Abdul Fettah BUYUK, ๑ Amir MEHBOD
}

Twin Cities Spine Center, Minneapolis, USA

\begin{abstract}
Objective: To evaluate patient-reported outcome measures and reoperation rates after primary fusion surgery from the thoracolumbar spine to the sacrum for adult spinal deformity (ASD).

Materials and Methods: In this study, 63 patients with ASD who underwent primary fusion surgery from the sacrum to thoracolumbar area at a single specialty spine centre were reviewed. All patients were followed-up for a minimum of 2 years with a mean follow-up period of 44 months. The preoperative and final follow-up Oswestry disability index (ODI) scores and radiographs were reviewed. Patients who reached a minimal clinically important difference (MCID) were determined. Moreover, reoperations for any reason during follow-up were noted.

Results: The median ODI scores improved significantly from 40 preoperatively to 28 at the final follow-up $(p \leq 0.01)$. A majority of patients achieved MCID (52\%), and reoperation was performed in $33 \%$ of the patients. The reasons for reoperation were proximal junctional failure ( $n=7)$, implant irritation $(n=5)$, pseudarthrosis repair $(n=4)$, infection $(n=4)$ and recurrent stenosis $(n=1)$.

Conclusion: Primary instrumented fusion from the thoracolumbar spine to the sacrum for ASD is associated with high re-operation rates. A significant improvement in ODI was seen at the final follow-up in patients who did not receive a re-operation. Whereas, among the re-operated patients, only $19 \%$ achieved a MCID in ODI score.

Keywords: Adult spinal deformity, reoperation, MCID, ODI, clinical outcomes
\end{abstract}

\section{INTRODUCTION}

Adult spinal deformity (ASD) can be a relatively painless condition or cause intractable pain. While the minimally symptomatic patients can be treated non-operatively with medication and physical therapy, patients with severe symptoms may require surgical intervention ${ }^{(1,2)}$. Although surgery for ASD has been shown to improve function and alleviate pain, it is unfortunately associated with high complication and re-operation rates ${ }^{(3-5)}$. Moreover, surgical options can vary between minimally invasive decompressions to long construct fusions ${ }^{(4)}$. Many studies have evaluated the results of ASD surgery with different inclusion criteria, fusion levels and outcome assessments. Surgical procedures are typically multilevel and can often include the sacrum distally. Ending a construct at L5 instead of the sacrum has its own advantages and limitations. The advantages include it being less invasive, preserving lumbosacral motion and avoiding pseudarthrosis at that level, while the limitations are generally degeneration and loss of lordosis at L5-S1 leading to additional surgery due to axial pain, radiculopathy or sagittal imbalance ${ }^{(6)}$. In addition, the known complications when including the sacrum are pseudarthrosis, proximal junctional kyphosis and proximal junctional failure (PJF) ${ }^{(7,8)}$. This retrospective study evaluated patient-reported outcome measures and reoperation rates after primary instrumented fusion from the thoracolumbar area to the sacrum. Understanding the outcomes and possible complications leading to re-operation will help surgeons and their patients make informed treatment decisions and manage both the pre- and postoperative expectations.

\section{MATERIALS AND METHODS}

Ethics committee approval was obtained from Allina Health Institutional Review Board (no: 1403801). Institutional Review Board waived for this type of study.

This study has been approved by the institutional review board prior to the retrospective chart review and radiographic assessment. The study included consecutive patients with ASD who underwent surgery at a single specialty spine centre between 2008 and 2016. ASD was defined as a Cobb angle

Address for Correspondence: Abdul Fettah Buyuk, Twin Cities Spine Center, Minneapolis, USA

Phone: +1 6127756200 E-mail: afettahbuyuk@hotmail.com Received: 25.02.2020 Accepted: 28.06.2020

ORCID ID: orcid.org/0000-0003-0316-5444 
of $30^{\circ}$ or greater or/and a sagittal vertical axis (SVA) of $5 \mathrm{~cm}$ or greater or/and pelvic tilt (PT) $>25^{\circ}$. All included patients had at least five-level primary instrumented fusions from the sacrum-pelvis to the upper lumbar or thoracic spine (T9-L1). However, patients with prior lumbar fusion surgery, severe osteoporosis, neuromuscular disorders, infection or trauma and those who refused to be included were excluded from the study. Additionally, patients who had surgery within two years prior to the initiation of the study were also deemed ineligible to be included.

\section{Statistical Analysis}

Moreover, data were extracted from the patients' clinical and operative notes in the electronic health records of our local hospital system. Functional outcome analysis was based on the Oswestry disability index (ODI) before surgery and at the final follow-up. For further clinical outcome evaluation, the minimal clinically important difference (MCID) was calculated; and the threshold for MCID was $12.8^{(9)}$. In addition, the number of instrumented levels, the surgical approach and whether iliac fixation or osteotomy (Smith-Petersen) was performed were assessed. Additionally, re-operation during follow-up for any reason was recorded. Radiographic measurements were done on digitally archived posterior-anterior and lateral radiographs from two time points-preoperative and at final follow-up or pre-revision. Statistical tests included chi-square or Fisher's exact tests for categorical variables, Student's t-tests and paired t-tests for normally distributed continuous variables and Kruskal-Wallis tests for non-normally distributed data. The threshold for statistical significance was $\mathrm{p}=0.05$.

\section{RESULTS}

In total, 449 fusion cases were reported between 2008 and 2016. Of these, 210 were excluded due to a history of previous spine fusion. Among the 239 primary cases, 167 patients had instrumented fusion proximal to S1. Moreover, 72 patients received instrumented posterior fusion from the lower thoracolumbar spine (T9-L1) to the sacrum with or without pelvic extension. Nine patients were excluded due to a history of osteomyelitis $(n=1)$, no consent to research $(n=2)$, and failure to follow-up $(n=6)^{(6)}$. Finally, 63 patients were eligible for the study (Table 1). These were nine males and 54 females. Their mean age was 63 years. While the median follow-up was 34 months, the median number of levels fused was seven. For $80 \%$ of the patients, the uppermost instrumented level was T10 or T11. Most patients (91\%) received an interbody fusion implant in addition to posterior screws and rods. Fixation to the pelvis was employed in two-thirds of the subjects. All patients received either interbody fusion or pelvic fixation, or both, at L5-S1, depending on surgeon's preference. Additionally, SmithPetersen osteotomies were performed in $29 \%$ of the patients. Table 2 summarises the radiographic data and compares the variables between patients receiving a re-operation due to PJF and the other study subjects. A significant improvement was observed in their lumbar lordosis in both groups; however, patients who were re-operated due to PJF had smaller changes in their lumbar lordosis and SVA. In addition, patients reoperated for PJF had a larger preoperative and postoperative PT. While the PT improvement was significant in non-PJF patients, it was insignificant in patients who had PJF.

Interestingly, a 30\% improvement (Table 3 ) in the patientreported outcomes (mean ODI scores) was observed among all patients (i.e. from 40 preoperatively to 28 at the final followup), which was significant $(p<0.01)$. Among the patients who were re-operated, the change in ODI was -4 points. The final outcome for these patients (46 points) was statistically different from the patients who did not receive a reoperation, whose final outcome was 20 points ( $p=0.01$ ). Of the total study population, $52 \%$ of the patients achieved MCID in ODI (Table 4). While the patients who were re-operated achieved only $19 \%$ MCID, those who were not, achieved a $69 \%$ MCID. The difference between the two groups was therefore significant $(p<0.01)$.

Further, re-operations during the follow-up period were performed on 21 of the 63 included patients (33\%) (Table 5). The reasons for re-operation included PJF $(n=7)$, implant irritation $(n=6)$, pseudarthrosis repair $(n=4)$, surgical site infection $(n=4)$ and recurrent stenosis $(n=1)$. One subject, however, presented with both infection and pseudarthrosis.

\section{DISCUSSION}

In a prospective observational study comparing non-operative and operative treatments for symptomatic ASD, patients showed significant improvement with surgical treatment ${ }^{(10)}$.

Table 1. Demographics and surgical factors

\begin{tabular}{ll}
\hline Factor, measure (statistic) & $\begin{array}{l}\text { All patients } \\
(\mathbf{n}=63)\end{array}$ \\
\hline Age, years (mean \pm SD) & $62.9 \pm 9.8$ \\
\hline Gender (M:F) & $9: 54$ \\
\hline BMI (mean \pm SD) & $28.6 \pm 5.9$ \\
\hline Follow up, months (median, range) & $34(24-103)$ \\
\hline Number of fused levels (median, range) & $7(5-9)$ \\
\hline Upper instrumented level, $\mathbf{n}$ & \\
\hline T9 & $4(6 \%)$ \\
\hline T10 & $25(40 \%)$ \\
\hline T11 & $25(40 \%)$ \\
\hline T12 & $8(13 \%)$ \\
\hline L1 & $1(2 \%)$ \\
\hline Interbody procedure, $n$ & $39(62 \%)$ \\
\hline ALIF & $18(29 \%)$ \\
\hline XLIF and/or TLIF & $6(10 \%)$ \\
\hline No interbody & $40 / 63$ (63\%) \\
\hline Iliac fixation, $n$ (\%) & $18 / 63$ (29\%) \\
\hline Osteotomy, $n$ (\%) & \\
\hline SD: Standard deviation, $n:$ Number, M: Male, F: Female, BMI: Body mass \\
index, ALIF: Anterior lumbar interbody fusion XLIF: Extreme lateral \\
interbody fusion, TLIF: Transforaminal lumbar interbody fusion
\end{tabular}


Among the operative subjects, the mean pre- to postoperative improvement in ODI was 14 , however, there was no significant change in patients treated non-operatively. In other study comparing changes in back and leg back pain after operative or non-operative treatment, a significant improvement with surgical intervention was observed. Of the surgically treated

Table 2. Radiographic parameters for patients with and without proximal junctional failure

\begin{tabular}{|c|c|c|c|c|}
\hline Factor & $\begin{array}{l}\text { All patients } \\
(n=63)\end{array}$ & $\begin{array}{l}\text { PJF } \\
(n=7)\end{array}$ & $\begin{array}{l}\text { No PJF } \\
(n=56)\end{array}$ & $p$ value \\
\hline \multicolumn{5}{|l|}{ Lumbar lordosis, degrees (mean \pm SD) } \\
\hline Preoperative & $36 \pm 17$ & $35 \pm 16$ & $36 \pm 17$ & \multirow{4}{*}{0.30} \\
\hline Final follow-up & $52 \pm 12$ & $48 \pm 14$ & $53 \pm 12$ & \\
\hline $\mathrm{p}$ value (preoperative vs final) & $<0.01$ & $<0.01$ & $<0.01$ & \\
\hline Delta (preoperative-final) & - & $-12 \pm 10$ & $-17 \pm 14$ & \\
\hline Pelvic incidence, degrees (mean \pm SD) & $57 \pm 10$ & $58 \pm 10$ & $56 \pm 10$ & 0.63 \\
\hline \multicolumn{5}{|l|}{ Pelvic tilt, degrees (mean \pm SD) } \\
\hline Preoperative & $24 \pm 7$ & $27 \pm 9$ & $24 \pm 7$ & \multirow{4}{*}{0.57} \\
\hline Final follow-up & $22 \pm 8$ & $25 \pm 6$ & $21 \pm 8$ & \\
\hline$p$ value (preoperative vs final) & $<0.01$ & 0.28 & $<0.01$ & \\
\hline Delta (preoperative-final) & - & $1 \pm 6$ & $3 \pm 7$ & \\
\hline \multicolumn{5}{|l|}{ SVA, mm (mean \pm SD) } \\
\hline Preoperative & $50 \pm 50$ & $30 \pm 50$ & $52 \pm 50$ & \multirow{4}{*}{0.10} \\
\hline Final follow-up & $29 \pm 37$ & $25 \pm 47$ & $30 \pm 37$ & \\
\hline$p$ value (preoperative vs final) & $<0.01$ & 0.37 & $<0.01$ & \\
\hline Delta (preoperative-final) & - & $5 \pm 23$ & $23 \pm 45$ & \\
\hline \multicolumn{5}{|l|}{ Coronal cobb angle degrees (mean \pm SD) } \\
\hline Preoperative & $42 \pm 13$ & $41 \pm 10$ & $43 \pm 14$ & \multirow{4}{*}{0.71} \\
\hline Final follow-up & $19 \pm 9$ & $16 \pm 10$ & $19 \pm 9$ & \\
\hline $\mathrm{p}$ value (preoperative vs final) & $<0.01$ & $<0.01$ & $<0.01$ & \\
\hline Delta (preoperative-final) & - & $25 \pm 6$ & $24 \pm 10$ & \\
\hline \multicolumn{5}{|c|}{ Coronal plane decompensation, $\mathrm{mm}$ (mean $\pm \mathrm{SD}$ ) } \\
\hline Preoperative & $26 \pm 26$ & $15 \pm 13$ & $29 \pm 27$ & \multirow{4}{*}{0.08} \\
\hline Final follow-up & $15 \pm 13$ & $10 \pm 11$ & $15 \pm 13$ & \\
\hline$p$ value (preoperative vs final) & $<0.01$ & 0.02 & $<0.01$ & \\
\hline Delta (preoperative-final) & - & $5 \pm 7$ & $13 \pm 23$ & \\
\hline
\end{tabular}

PJF: Proximal junctional failure, n: Number, SD: Standard deviation, SVA: Sagittal vertical axis

Table 3. Patient reported outcomes (median, range)

\begin{tabular}{lllll} 
Patient reported outcome & All patients $(n=63)$ & Re-operation $(n=21)$ & No re-operation $(n=42)$ & $p$ value \\
\hline Preoperative ODI & $40(8-80)$ & $42(8-67)$ & $39(16-80)$ & 0.98 \\
\hline Postoperative ODI & $28(0-82)$ & $46(0-82)$ & $20(0-80)$ & 0.01 \\
\hline p value & $<0.01$ & 0.97 & $<0.01$ & - \\
\hline
\end{tabular}

ODI: Oswestry disability index, n: Number

Table 4. Patients achieving a minimal clinically important difference on Oswestry disability index

\begin{tabular}{lllll} 
MCID & All patients $(n=63)$ & Re-operation $(n=21)$ & No re-operation $(n=42)$ & p value \\
\hline Yes (percent) & $33(52 \%)$ & $4(19 \%)$ & $29(69 \%)$ & $<0.01$ \\
\hline No (percent) & $30(48 \%)$ & $17(81 \%)$ & $13(31 \%)$ &
\end{tabular}

MCID: Minimal clinically important difference, $n$ : Number 


\begin{tabular}{lllll}
\hline Table 5. Reasons for re-operation & & & & \\
\hline Reason for re-operation & Number & $\begin{array}{l}\text { Study } \\
\text { population } \\
(\mathrm{n=63)} \%\end{array}$ & $\begin{array}{l}\text { Re-operated } \\
\text { patients } \\
(\mathrm{n}=21), \%\end{array}$ & $\begin{array}{l}\text { Months to occurrence } \\
\text { median } \\
\text { (range) }\end{array}$ \\
\hline Surgical site infection & 4 & $6 \%$ & $19 \%$ & $1(0-40)$ \\
\hline Proximal junctional failure & 7 & $11 \%$ & $33 \%$ & $12(6-50)$ \\
\hline Pseudoarthrosis & 4 & $6 \%$ & $19 \%$ & $14(12-29)$ \\
\hline Painful instrumentation & 6 & $10 \%$ & $29 \%$ & $16(8-35)$ \\
\hline Recurrent symptoms & 1 & $2 \%$ & $5 \%$ & 30 \\
\hline n: Number & & & &
\end{tabular}

patients, $49 \%$ achieved MCID, while $<10 \%$ of the non-operative patients achieved $\mathrm{MCID}^{(11)}$. Our study also showed an overall significant improvement in ODI with surgical treatment (40 preoperatively to 28 at the final follow-up). Additionally, $52 \%$ of our subjects achieved MCID.

Typically, re-operation after primary fusion surgery for ASD is reportedly high. Transfeldt et al.(12) reported $37 \%$ re-operation rate among patients with long fusions for degenerative scoliosis with radiculopathy. Likewise, Mok et al. ${ }^{(13)}$ reported a $26 \%$ reoperation rate including infection, adjacent segment problems, implant failure, painful implant or pseudarthrosis. They included patients with long fusion (least five levels). Instrumented levels varied both proximally and distally. We were more homogeneous in terms of always including the sacrum and ending at the upper lumbar/lower thoracic spine, but we still observed a high re-operation rate (33\%). Our reasons for re-operation were similar to other findings: PJF, painful implant, pseudarthrosis, infection and recurrent stenosis. Apparently, one-third of ASD patients receiving multilevel surgery are at risk for reoperation.

PJF is one of the main reason for re-operation after adult spine deformity. Its incidence in the literature has been reported between $1 \%$ and $35 \%^{(7)}$. The aetiology of PJF is most likely multifactorial and several risk factors have been defined for PJF, including fusion to the sacrum-pelvis, anterior-posterior combined fusion and upper-instrumented vertebra level at the thoracolumbar junction ${ }^{(7,14)}$. Yagi et al. ${ }^{(15)}$, in their study, reported a $1.4 \%$ incidence of PJF in surgically treated ASD patients with a minimum of two-year follow-up. Park et al. ${ }^{(14)}$ reported an $18 \%$ PJF in patients who underwent a long instrumented fusion to the sacrum for ASD. In this study, PJF was the main reason for re-operation. Its overall incidence was $11 \%$, and it accounted for one-third of the re-operated patients. The high incidence of PJF in this study may be related to our surgical inclusion criteria where all patients had fusion to sacrum-pelvis and their upperinstrumented vertebra level were at thoracolumbar junction. In addition, most of our patients had anterior-posterior-combined surgeries and only pedicle screws were utilised for posterior instrumentation. Our radiographic results showed that patients had significant improvement in their lumbar lordosis and mild changes in their SVA. However, patients who had PJF had higher pre- and postoperative PT. Additionally, improvement in PT was significant in patients who did not develop PJF and insignificant for patients who did. Higher preoperative PT was reported as a risk factor for PJF, and patients who continue to have high PT postoperatively can be evaluated as having under correction of their sagittal alignment ${ }^{(16)}$.

Pseudarthrosis after primary fusion surgery for ASD can be painful and may require re-operation. In a meta-analysis of pseudarthrosis in adult and paediatric spinal deformity surgery, a $6.3 \%$ incidence of pseudarthrosis has been reported ${ }^{(17)}$. Including the sacrum is a risk factor for pseudarthrosis ${ }^{(6,18)}$. Kim et al. ${ }^{(18)}$ reported a $24 \%$ incidence of pseudarthrosis after long instrumentation to the sacrum in ASD patients. Further, after a combination of sacral screws and iliac screws, Tsuchiya et al. ${ }^{(19)}$ reported a $7.5 \%$ non-union in their study. Our results showed $6 \%$ pseudarthrosis requiring revision surgery. While all of our patients had fusion to sacrum, the vast majority also had supplemental pelvic fixation. Our relatively lower rate of pseudarthrosis might be related to this utilisation of pelvic fixation. In addition, the large majority of our patients (92\%) had interbody fusion at the L5/S1 level. Schroder reported that a high fusion rate can be expected with the usage of interbody fusion (anterior lumbar interbody fusion or transforaminal lumbar interbody fusion) at the treatment of L5/S1 degenerative pathologies $^{(20)}$.

Despite their efficacy, iliac screws can themselves be a source of pain or irritation that requires implant removal. In one study, $6.1 \%$ of ASD patients who had fusion to the sacrum required removal of iliac screws ${ }^{(21)}$. In our study, removal of painful iliac instrumentation was required in six of 63 patients (10\%); 40 patients had iliac screws for pelvic fixation, which means $25 \%$ incidence of painful implants in this subgroup. All patients reported relief without sequelae after iliac screw removal.

The surgical site infection after primary fusion surgery for ASD is a frequent complication with a reported incidence of 1.2 $10.9 \%^{(22-24)}$. Within the deformity population in our study that underwent surgery, $6 \%$ had surgical site infections requiring reoperation, which is consistent with the literature. The median time to presentation was one month. One patient was treated with irrigation and debridement and others with vacuumassisted wound closure. All patients were infection free at their final follow-up. 
Symptomatic recurrent or remnant stenosis after spine surgery has been described and re-operation was considered as an appropriate treatment option for patients having predominant leg or mixed leg/back pain ${ }^{(25)}$. In this study, recurrent leg pain and foraminal stenosis was confirmed in one patient through diagnostic imaging studies. Diagnosis was also supported with selective nerve root block. This subject underwent decompression surgery during follow-up with significant improvement.

We found that reoperation and patient-reported outcomes were related. Patients who received a re-operation expressed lower patient-reported outcome measures at the final follow-up compared to those who did not. A number of investigators have established relationships between reoperation and clinical symptoms ${ }^{(13,26-28)}$, however, the link between patient-reported outcomes and reoperation rates is novel.

\section{Study Limitations}

Our study has several limitations, which create bias. First, being a retrospective study, we cannot adjust for statistical power nor can we establish causation between pre- and postoperative factors. Second, patients who were lost to follow-up or who did not consent to participate were excluded from the study. Results could have been different if all patients were included. Third, there were a considerable number of patients with a history of previous fusion who were excluded from this study; therefore, our results are applicable to patients receiving primary fusion surgery and cannot be generalised to the whole population of adults with deformity and those who are candidates for fusion surgery. Fourth, the follow-up periods varied between subjects. Patient-reported outcomes are subject to change over time, especially with the onset of new symptoms. Last, results could have been different if fusions had been extended to the pelvis for all patients.

\section{CONCLUSION}

A significant improvement was seen in patient-reported outcome measures in the patients who underwent primary fusion from the thoracolumbar spine to the sacrum for ASD. MCID was achieved in the majority of patients. The rate for reoperation was high; one-third of the patients had revision (33\%) at long-term follow-up. Moreover, knowing potential expected clinical outcomes and possible reasons for re-operation in ASD surgery is important for counselling patients and managing their expectations.

Acknowledgment: The authors wish to acknowledge the encouragement and support of Ensor E. Transfeldt, MD and John M. Dawson, PhD.

\section{Ethics}

Ethics Committee Approval: Ethics committee approval was obtained from Allina Health Institutional Review Board (no: 1403801).

Informed Consent: Institutional Review Board waived for this type of study.
Peer-review: Externally and internally peer-reviewed.

\section{Authorship Contributions}

Concept: A.F.B., A.M., Design: A.F.B., A.M., Data Collection or Processing: A.F.B., Analysis or Interpretation: A.F.B., A.M., Literature Search: A.F.B., A.M., Writing: A.F.B., A.M.

Conflict of Interest: No conflict of interest was declared by the authors.

Financial Disclosure: The authors declared that this study received no financial support.

\section{REFERENCES}

1. Berven SH, Deviren V, Mitchell B, Wahba G, Hu SS, Bradford DS Operative management of degenerative scoliosis: an evidence-based approach to surgical strategies based on clinical and radiographic outcomes. Neurosurg Clin N Am. 2007;18:261-72.

2. Tribus CB. Degenerative lumbar scoliosis: evaluation and management. J Am Acad Orthop Surg. 2003;11:174-83.

3. Ames $C P$, Scheer JK, Lafage $V$, Smith JS, Bess $S$, Berven $S H$, et al. Adult spinal deformity: epidemiology, health impact, evaluation, and management. Spine Deform. 2016;4:310-22.

4. Daubs MD, Lenke LG, Cheh G, Stobbs G, Bridwell KH. Adult spinal deformity surgery: Complications and outcomes in patients over age 60. Spine. 2007;32:2238-44.

5. Smith JS, Sansur CA, Donaldson WF, Perra JH, Mudiyam R, Choma TJ, et al. Short-term morbidity and mortality associated with correction of thoracolumbar fixed sagittal plane deformity: a report from the Scoliosis Research Society Morbidity and Mortality Committee. Spine. 2011;36:958-64.

6. Edwards CC, Bridwell KH, Patel A, Rinella AS, Berra A, Lenke LG. Long adult deformity fusions to $L 5$ and the sacrum a matched cohort analysis. Spine. 2004;29:1996-2005.

7. Nguyen NL, Kong CY, Hart RA. Proximal junctional kyphosis and failure-diagnosis, prevention, and treatment. Curr Rev Musculoskelet Med. 2016;9:299-308.

8. Weistroffer JK, Perra JH, Lonstein JE, Schwender JD, Garvey TA Transfeldt EE, et al. Complications in long fusions to the sacrum for adult scoliosis: minimum five-year analysis of fifty patients. Spine. 2008;33:1478-83.

9. Copay AG, Glassman SD, Subach BR, Berven S, Schuler TC, Carreon LY. Minimum clinically important difference in lumbar spine surgery patients: a choice of methods using the Oswestry Disability Index, Medical Outcomes Study questionnaire Short Form 36, and pain scales. Spine J. 2008;8:968-74.

10. Bridwell KH, Glassman S, Horton W, Shaffrey C, Schwab F, Zebala LP, et al. Does treatment (nonoperative and operative) improve the two-year quality of life in patients with adult symptomatic lumbar scoliosis: a prospective multicenter evidence-based medicine study. Spine. 2009;34:2171-8.

11. Scheer JK, Smith JS, Clark AJ, Lafage V, Kim HJ, Rolston JD, et al. International Spine Study Group: Comprehensive study of back and leg pain improvements after adult spinal deformity surgery: analysis of 421 patients with 2-year follow-up and of the impact of the surgery on treatment satisfaction. J Neurosurg Spine. 2015;22:540-53.

12. Transfeldt EE, Topp R, Mehbod AA, Winter RB. Surgical outcomes of decompression, decompression with limited fusion, and decompression with full curve fusion for degenerative scoliosis with radiculopathy. Spine. 2010;35:1872-5.

13. Mok JM, Cloyd JM, Bradford DS, Hu SS, Deviren V, Smith JA, et al. Reoperation after primary fusion for adult spinal deformity: rate, reason, and timing. Spine. 2009;34:832-9.

14. Park SJ, Lee CS, Chung SS, Lee JY, Kang SS, Park SH. Different risk factors of proximal junctional kyphosis and proximal junctional failure following long instrumented fusion to the sacrum for adult spinal deformity: survivorship analysis of 160 patients. Neurosurgery. 2017;80:279-86. 
15. Yagi M, Rahm M, Gaines R, Maziad A, Ross T, Kim HJ, et al. Characterization and surgical outcomes of proximal junctional failure in surgically treated patients with adult spinal deformity. Spine. 2014;39:E607-14.

16. Yang J, Khalifé $\mathrm{M}$, Lafage $\mathrm{R}$, Kim HJ, Smith J, Shaffrey $\mathrm{Cl}$, et al. What factors predict the risk of proximal junctional failure in the long term, demographic, surgical, or radiographic?: results from a timedependent ROC curve. Spine (Phila Pa 1976). 2019;44:777-84.

17. How NE, Street JT, Dvorak MF, Fisher CG, Kwon BK, Paquette S, et al. Pseudarthrosis in adult and pediatric spinal deformity surgery: a systematic review of the literature and meta-analysis of incidence, characteristics, and risk factors. Neurosurg Rev. 2018;42:319-36.

18. Kim YJ, Bridwell KH, Lenke LG, Rhim S, Cheh G. Pseudarthrosis in long adult spinal deformity instrumentation and fusion to the sacrum: prevalence and risk factor analysis of 144 cases. Spine. 2006;31:2329-36.

19. Tsuchiya K, Bridwell KH, Kuklo TR, Lenke LG, Baldus C. Minimum 5-year analysis of L5-S1 fusion using sacropelvic fixation (bilateral S1 and iliac screws) for spinal deformity. Spine. 2006;31:303-8.

20. Schroeder GD, Kepler CK, Millhouse PW, Fleischman AN, Maltenfort MG, Bateman DK, et al. L5/S1 fusion rates in degenerative spine surgery: a systematic review comparing ALIF, TLIF, and Axial Interbody Arthrodesis. Clin Spine Surg. 2016;29:150-5.

21. O'Shaughnessy BA, Lenke LG, Bridwell KH, Cho W, Zebala LP, Chang MS, et al. Should symptomatic iliac screws be electively removed in adult spinal deformity patients fused to the sacrum? Spine. 2012;37:1175-81.
22. Pull ter Gunne AF, van Laarhoven C], Cohen DB. Incidence of surgical site infection following adult spinal deformity surgery: an analysis of patient risk. Eur Spine J 2010;19:982-8.

23. Shillingford JN, Laratta JL, Reddy H, Ha A, Lehman RA Jr, Lenke LG, et al. Postoperative surgical site infection after spine surgery: an update from the Scoliosis Research Society (SRS) Morbidity and Mortality Database. Spine Deform. 2018;6:634-43.

24. Theologis AA, Demirkiran G, Callahan M, Pekmezci M, Ames C, Deviren $\mathrm{V}$. Local intrawound vancomycin powder decreases the risk of surgical site infections in complex adult deformity reconstruction: a cost analysis. Spine. 2014;39:1875-80.

25. Tronnier VM, Eldabe S, Franke J, Huygen F, Rigoard P, de Andres Ares J, et al. The appropriate management of persisting pain after spine surgery: a European panel study with recommendations based on the RAND/UCLA method. Eur Spine J. 2018;28:31-45.

26. Hamilton DK, Kanter AS, Bolinger BD, Mundis GM Jr, Nguyen $S$, Mummaneni PV, et al. Reoperation rates in minimally invasive, hybrid and open surgical treatment for adult spinal deformity with minimum 2-year follow-up. Eur Spine J. 2016;25:2605-11.

27. Pichelmann MA, Lenke LG, Bridwell KH, Good CR, O'Leary PT, Sides BA. Revision rates following primary adult spinal deformity surgery: six hundred forty-three consecutive patients followed-up to twentytwo years postoperative. Spine. 2010;35:219-26.

28. Sánchez-Mariscal F, Gomez-Rice A, Izquierdo E, Pizones ], Zúñiga L, Álvarez-González P. Survivorship analysis after primary fusion for adult scoliosis, prognostic factors for reoperation. Spine J. 2014;14:1629-34. 